First publ. in: Global Change Biology 13 (2007), 7, pp. 1314-1326

\title{
Large-scale climatic signatures in lakes across Europe: a meta-analysis
}

\author{
THORSTEN BLENCKNER*, RITA ADRIAN†, DAVID M. LIVINGSTONE \\ ELEANOR JENNINGS§, GESA A. WEYHENMEYER-, D. GLEN GEORGE\|, \\ THOMAS JANKOWSKIt, MARKO J ̈̈RVINEN ${ }^{* *}$, CAITRIONA NIC AONGHUSA††,

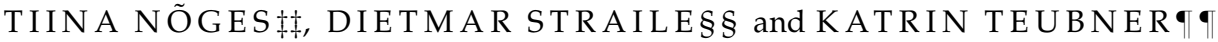 \\ *Erken Laboratory, Department of Ecology and Evolution, Evolutionary Biology Centre, Uppsala University, Norr Malma 4200, \\ SE-761 73 Norrtälje, Sweden, †Leibniz-Institute of Freshwater Ecology and Inland Fisheries, Müggelseedamm 301, D-12587 Berlin, \\ Germany, $\ddagger$ Water Resources Department, Swiss Federal Institute of Aquatic Science and Technology (Eawag), Überlandstrasse 133, \\ CH-8600 Dübendorf, Switzerland, §Centre for the Environment, School of Natural Sciences, Trinity College Dublin, Dublin 2, \\ Ireland, Department of Environmental Assessment, Swedish University of Agricultural Sciences (SLU), Box 7050, \\ SE-750 07 Uppsala, Sweden, ||Centre for Ecology and Hydrology, Lancaster Environment Centre, Library Avenue, Bailrigg, \\ Lancaster LA1 4RA, UK, ${ }^{* *}$ Lammi Biological Station, University of Helsinki, Paajarventie 320, FIN-16900 Lammi, Finland, \\ $\dagger \dagger$ Marine Institute, Furnace, Newport, Co. Mayo, Ireland, ††Centre for Limnology, Institute of Agricultural and Environmental \\ Sciences, Estonian University of Life Sciences, EE-61101 Rannu, Tartumaa, Estonia, §§Limnological Institute, University of \\ Konstanz, Mainaustrasse 252, D-78457 Konstanz, Germany, -Department of Freshwater Ecology, Faculty of Life Sciences, \\ University of Vienna, Althanstrasse 14, A-1090 Vienna, Austria
}

\begin{abstract}
Recent studies have highlighted the impact of the winter North Atlantic Oscillation (NAO) on water temperature, ice conditions, and spring plankton phenology in specific lakes and regions in Europe. Here, we use meta-analysis techniques to test whether $\mathbf{1 8}$ lakes in northern, western, and central Europe respond coherently to winter climate forcing, and to assess the persistence of the winter climate signal in physical, chemical, and biological variables during the year. A meta-analysis approach was chosen because we wished to emphasize the overall coherence pattern rather than individual lake responses. A particular strength of our approach is that time-series from each of the $\mathbf{1 8}$ lakes were subjected to the same robust statistical analysis covering the same 23-year period. Although the strongest overall coherence in response to the winter NAO was exhibited by lake water temperatures, a strong, coherent response was also exhibited by concentrations of soluble reactive phosphorus and soluble reactive silicate, most likely as a result of the coherent response exhibited by the spring phytoplankton bloom. Lake nitrate concentrations showed significant coherence in winter. With the exception of the cyanobacterial biomass in summer, phytoplankton biomass in all seasons was unrelated to the winter NAO. A strong coherence in the abundance of daphnids during spring can most likely be attributed to coherence in daphnid phenology. A strong coherence in the summer abundance of the cyclopoid copepods may have been related to a coherent change in their emergence from resting stages. We discuss the complex nature of the potential mechanisms that drive the observed changes.
\end{abstract}

Keywords: climate variability, coherence, European lakes, meta-analysis, nutrients, phytoplankton, water temperature, zooplankton

Received 26 June 2006; revised version received 17 January 2007 and accepted 26 January 2007

Correspondence: Thorsten Blenckner, tel. +46 176 229000, fax +46 176 229421, e-mail: Thorsten.Blenckner@geo.uu.se
Introduction

Lake ecosystems are strongly influenced by many stressors (e.g. eutrophication, climate change, acidification, and pollution). Physically, the most important drivers are the local meteorological variables air temperature, 
wind speed, cloud cover, and relative humidity (Edinger et al., 1968). However, it is now clear that large-scale coherence in some of these forcing variables, especially air temperature, can result in a similar coherence also being exhibited by many internal lake variables (e.g. Magnuson et al., 1990). In North America, much research has been conducted recently into the effects of the El-Niño/Southern Oscillation (ENSO) climate phenomenon, which is known to have a strong effect on the climate from the Americas through south-east Asia to east Africa (Wang \& Fiedler, 2006 and references therein). The North Atlantic Oscillation (NAO) determines the winter climate variability of much of Europe and large areas of northern Asia (Walker \& Bliss, 1932; Hurrell, 1995). It describes the atmospheric mass balance between the Azores High and the Iceland Low. Highly positive winter NAO indices indicate steep surface pressure gradients and strong zonal circulation over the North Atlantic, leading to mild and rainy winters in the western and northern parts of Europe. The reverse situation is associated with low surface pressure gradients and weaker zonal circulation over the North Atlantic, usually bringing cold winters to much of Europe (Hurrell, 1995).

Climatic forcing governs many of the physical aspects of lake ecosystems - including water temperatures and the formation and thawing of lake ice - which, directly or indirectly, affect the physiology, life history, and development of plankton and fish communities. Climate may also affect the dispersal of species (Thomas et al., 2004). Thus, climate warming is very likely to have a pronounced effect on lake ecosystems (Walther et al., 2002). The NAO winter index has been confirmed to be a valuable tool in the investigation of climate-induced changes in aquatic and terrestrial ecosystems (Ottersen et al., 2001; Blenckner \& Hillebrand, 2002). Variations in the winter NAO are known to be reflected in the temperatures of lake epilimnia and hypolimnia and in the timing of ice cover (Livingstone, 2000; Gerten \& Adrian, 2001; Livingstone \& Dokulil, 2001; Straile et al., 2003a, b). However, the nature of the response of lakes to climatic forcing is not necessarily geographically uniform: it can be influenced by latitude and longitude (Blenckner \& Hillebrand, 2002) and altitude (Livingstone et al., 2005). The timing of lake ice break-up, for example, which strongly influences the timing of spring algal blooms (Gerten \& Adrian, 2000), appears to respond to changes in air temperature in a nonlinear fashion, with the strength of the response depending on mean ambient air temperature, and hence on latitude (Weyhenmeyer et al., 2004). Daphnid populations in lakes several hundred kilometres apart appear to respond coherently to the NAO, specifically with regard to the timing of their population maximum, and consequently to the timing of the clear-water phase (Straile \& Adrian, 2000; Straile, 2002). These synchronous changes in phenology in lake ecosystems are consistent with the clear pattern of advances in plant flowering dates and in animal breeding dates found in terrestrial ecosystems (Walther et al., 2002) and in marine ecosystems (Edwards \& Richardson, 2004) that are associated with the NAO or ENSO (for reviews see Gerten \& Adrian, 2002a; Stenseth et al., 2002).

Climate-driven changes in the nutrient dynamics of lakes are less apparent. This is because such changes are difficult to distinguish from the effects of local reductions in nutrient loading (Anneville et al., 2004; Köhler et al., 2005; Nõges et al., 2005) and because of the complex way in which catchment characteristics (e.g. land use, the timing of run-off and the severity of frost) - can modify the effect of climate on nutrient loading (Blenckner, 2005). In a comparative investigation of the chemistry of lakes in Sweden, Weyhenmeyer (2004) found the highest degree of coherence among lakes to exist for variables which were closely linked to water temperature, and thus, to the NAO. In deep lakes and in marine systems, nutrient dynamics have been found to be affected by changing mixing/upwelling or runoff processes related to the NAO (Hagberg \& Tunberg, 2000; Oschlies, 2001; Straile et al., 2003a).

Although recent studies have highlighted the impacts of the NAO on lake plankton for specific sites and regions (for reviews see Gerten \& Adrian, 2002a; Straile et al., 2003b), here we provide for the first time a systematic, multi-country comparison of climateinduced changes in lakes using an ecosystem-level approach, in order to test whether the lakes respond coherently to large-scale winter climatic forcing, and to assess the persistence of the winter climate signal during the following year. We apply meta-analysis techniques to analyse patterns of coherence. A meta-analysis permits the statistical synthesis of research results from numerous individual studies that need not be related (Gurevitch et al., 1992), making possible the employment of an aggregate statistical test that is more powerful than statistical tests performed on the studies taken individually (Osenberg et al., 1999). It can give information on the overall magnitude of an effect, on whether that effect differs among contrasting categories of studies, and on how the variation is distributed within and among categories (similar to an analysis of variance). Moreover, a meta-analysis allows the factors (categories) that influence the overall pattern of coherence to be determined, and offers the additional advantage of allowing each individual study to be weighted by the number of samples included in the study.

An earlier meta-analysis of NAO effects based on published work provided a quantitative synthesis of the 
influence of the NAO on the timing of life history events, on the biomass of organisms, and on biomass on different trophic levels, and clearly demonstrated the presence of an NAO signature in freshwater, marine, and terrestrial ecosystems (Blenckner \& Hillebrand, 2002). Our study goes beyond the previous study of Blenckner \& Hillebrand (2002) by narrowing and deepening its focus to encompass multiple aspects of lake ecosystems, including water temperature, chemical variables, and phytoplankton and zooplankton communities at high taxonomic resolution. The lakes included in the current analysis represent a much broader range of lacustrine ecosystems than those included in the previous analysis. Moreover, in this study the metaanalysis was performed directly on one large, internally consistent dataset rather than on the results of previously published individual case studies. This provides a more statistically powerful test of the impacts of climatic forcing on lakes, while simultaneously avoiding the problems that are associated with publication bias and with discrepancies in the statistical protocols upon which the published data are based (Blenckner \& Hillebrand, 2002). In the current study, we test for climate-induced changes in 18 lakes located in three disparate geographical regions by studying the degree and extent to which interannual variations in the winter NAO influence physical, chemical, and biological variables. A particular strength of our approach is that for each of the 18 lakes, we conducted the same robust statistical analysis of time-series covering the same 23-year period. We chose the meta-analysis approach because we were interested not in the responses of individual lakes to the NAO, but in the overall pattern of coherence in physical, chemical, and biological variables existing among the lakes. In addition to investigating patterns of coherence, we also investigated the persistence exhibited by the NAO signal during the year. We discuss where and when we detect coherence in the response to the NAO, and use our detailed knowledge of the lakes under investigation to discuss some of the underlying mechanisms involved.

\section{Methods}

\section{Data and study sites}

The target variables upon which this study is based are: winter air temperature (no. of lakes $=n=10$; for some lakes situated close to one another, air temperature data from the same meteorological station were employed); surface water temperature $(n=18)$; near-bottom water temperature $(n=9)$; soluble reactive phosphorus (SRP, $n=12)$; total phosphorus (TP, $n=9)$; nitrate $\left(\mathrm{NO}_{3}^{-}\right.$, $n=9$ ); soluble reactive silicate (SRSi, $n=11$ ); the bio- masses of diatoms $(n=12)$, cyanobacteria $(n=12)$ and dinoflagellates $(n=9)$; the abundances of daphnids $(n=9)$, calanoid copepods $(n=6)$, cyclopoid copepods $(n=6)$, and total copepods $(n=4)$. All original data were sampled at intervals of between 1 week and 1 month. The data on the target variables were obtained from 18 limnologically diverse lakes (Table 1 and Fig. 1) located in three climatically distinct regions of Europe, here designated the Northern Region (Fennoscandia and Estonia), the Western Region (the United Kingdom and Ireland) and the Central Region (Germany, Switzerland, and Austria). The target variables were chosen a priori; these are the most important and the most common variables that are included in the long-term research programmes being conducted on the 18 lakes. Air and water temperatures were available for all lakes $(n=18)$, whereas this was not the case for nutrients, phytoplankton, and zooplankton (see Table 1). Thus, one needs to keep in mind that the results of this study do not necessarily hold for all of the lakes included in the study. It must also be kept in mind that our sample is biased towards large lakes, and therefore, the results will not necessarily hold for small lakes. With respect to the biological variables, we focused on the most common phytoplankton and zooplankton groups found in the lakes studied, except in the case of the cladocerans, for which we decided to focus on daphnids because they are often key species in lake plankton communities (Sommer et al., 1986). Phenological events, such as the timing of ice break-up and the timing of the spring phytoplankton and zooplankton maxima, have been analysed for some individual lakes (reviewed by Blenckner \& Hillebrand, 2002; Gerten \& Adrian, 2002a; Straile et al., 2003b). As the results of the metaanalysis of phenological events were essentially the same as those known already from the individual lake studies (earlier occurrence of cardinal events in positive $\mathrm{NAO}$ years and later occurrence in negative NAO years), we do not include these results here.

For each lake, the correlation coefficient $(r)$ of each of the target variables with the winter NAO index was computed for the 23-year period 1980-2002. Before computing $r$, all target variables and the NAO index were detrended to remove the effects of very lowfrequency variability. The detrending performed was either linear or, in the case of some nutrient time-series, logarithmic. The long-term changes in physical, chemical, and biological variables that occurred in some of the lakes during the study period, therefore, play only a minor role in this analysis. The NAO index used in this analysis was based on the principal component time series of the leading empirical orthogonal function of seasonal (December through March) sea level pressure anomalies over the Atlantic sector $\left(20^{\circ}-80^{\circ} \mathrm{N}\right.$, 
Table 1 The lakes studied, the eight characteristics employed in the meta-analysis, and the data available for each lake

\begin{tabular}{|c|c|c|c|c|c|c|c|c|c|}
\hline Lake & $\begin{array}{l}\text { Climate } \\
\text { region }\end{array}$ & $\begin{array}{l}\text { Mean } \\
\text { depth } \\
\text { (m) }\end{array}$ & $\begin{array}{l}\text { Maximum } \\
\text { depth }(m)\end{array}$ & $\begin{array}{l}\text { Critical } \\
\text { depth }(\mathrm{m})\end{array}$ & $\begin{array}{l}\text { Dynamic } \\
\text { ratio }\end{array}$ & $\begin{array}{l}\text { Residence } \\
\text { time (year) }\end{array}$ & $\begin{array}{l}\text { Ice } \\
\text { cover }\end{array}$ & $\begin{array}{l}\text { Trophic } \\
\text { status }\end{array}$ & $\begin{array}{l}\text { Available } \\
\text { data }\end{array}$ \\
\hline Pääjärvi, Finland (PA) & Northern & 15.3 & 85 & 6.7 & 0.2 & 3.5 & Yes & Oligo-mesotrophic & $\mathrm{A}, \mathrm{W}, \mathrm{N}, \mathrm{P}$ \\
\hline Erken, Sweden (ER) & Northern & 9 & 21 & 8.5 & 0.5 & 7 & Yes & Mesotrophic & $\mathrm{A}, \mathrm{W}, \mathrm{N}$ \\
\hline $\begin{array}{l}\text { Galten, Mälaren, } \\
\text { Sweden (GA) }\end{array}$ & Northern & 3.4 & 19 & 12.2 & 2.3 & 0.07 & Yes & Hypereutrophic & $\mathrm{A}, \mathrm{W}, \mathrm{N}, \mathrm{P}$ \\
\hline $\begin{array}{c}\text { Ekoln, Mälaren, } \\
\text { Sweden (EK) }\end{array}$ & Northern & 11.5 & 50 & 14.2 & 0.8 & 1.2 & YES & Eutrophic & $\mathrm{A}, \mathrm{W}, \mathrm{N}, \mathrm{P}, \mathrm{Z}$ \\
\hline Vättern, Sweden (VT) & Northern & 40 & 128 & 30.6 & 1.1 & 58 & No & Oligotrophic & $\mathrm{A}, \mathrm{W}, \mathrm{N}, \mathrm{P}$ \\
\hline Vänern, Sweden (VA) & Northern & 27 & 106 & 35.6 & 2.8 & 9 & No & Oligotrophic & $\mathrm{A}, \mathrm{W}, \mathrm{N}, \mathrm{P}, \mathrm{Z}$ \\
\hline Võrtsjärv, Estonia (VO) & Northern & 2.8 & 6 & 19.8 & 5.9 & 1.0 & Yes & Eutrophic & $\mathrm{A}, \mathrm{W}, \mathrm{N}, \mathrm{P}$ \\
\hline $\begin{array}{l}\text { Müggelsee, } \\
\text { Germany (MU) }\end{array}$ & Central & 4.9 & 8 & 5.1 & 0.6 & 0.17 & Yes & Eutrophic & $\mathrm{A}, \mathrm{W}, \mathrm{N}, \mathrm{P}, \mathrm{Z}$ \\
\hline $\begin{array}{l}\text { Lake Constance, } \\
\text { Germany (LC) }\end{array}$ & Central & 101 & 254 & 23.7 & 0.2 & 4.2 & No & Oligo-mesotrophic & $\mathrm{A}, \mathrm{W}, \mathrm{N}, \mathrm{P}, \mathrm{Z}$ \\
\hline $\begin{array}{l}\text { Greifensee, Switzerland } \\
\text { (GR) }\end{array}$ & Central & 17.7 & 34 & 5.5 & 0.2 & 1.1 & No & Eutrophic & $\mathrm{A}, \mathrm{W}, \mathrm{N}, \mathrm{P}, \mathrm{Z}$ \\
\hline $\begin{array}{l}\text { Walensee, Switzerland } \\
\text { (WA) }\end{array}$ & Central & 103 & 145 & 8.5 & 0.1 & 1.4 & No & Oligotrophic & $\mathrm{A}, \mathrm{W}, \mathrm{N}, \mathrm{P}, \mathrm{Z}$ \\
\hline $\begin{array}{l}\text { Upper Lake Zurich, } \\
\text { Switzerland (ZU) }\end{array}$ & Central & 23 & 48 & 7.9 & 0.2 & 0.16 & No & Oligotrophic & $\mathrm{A}, \mathrm{W}, \mathrm{N}, \mathrm{P}, \mathrm{Z}$ \\
\hline $\begin{array}{l}\text { Lower Lake Zurich, } \\
\text { Switzerland (ZL) }\end{array}$ & Central & 51 & 136 & 12.5 & 0.2 & 1.1 & No & Mesotrophic & $\mathrm{A}, \mathrm{W}, \mathrm{N}, \mathrm{P}, \mathrm{Z}$ \\
\hline Mondsee, Austria (MO) & Central & 36 & 68 & 6.8 & 0.1 & 1.7 & Yes & Oligo-mesotrophic & $\mathrm{A}, \mathrm{W}, \mathrm{N}$ \\
\hline $\begin{array}{l}\text { Lough Feeagh, } \\
\text { Ireland (LF) }\end{array}$ & Western & 14.5 & 45 & 3.9 & 0.1 & 0.47 & No & Oligotrophic & A, W \\
\hline $\begin{array}{l}\text { Lough Leane, } \\
\text { Ireland (LL) }\end{array}$ & Western & 13.4 & 60 & 7.9 & 0.3 & 0.57 & No & Mesotrophic & $\mathrm{A}, \mathrm{W}, \mathrm{N}$ \\
\hline $\begin{array}{l}\text { Windermere, } \\
\text { England (WI) }\end{array}$ & Western & 25.1 & 64 & 5.3 & 0.1 & 0.8 & No & Mesotrophic & $\mathrm{A}, \mathrm{W}, \mathrm{Z}$ \\
\hline $\begin{array}{l}\text { Esthwaite Water, } \\
\text { England (ES) }\end{array}$ & Western & 6.4 & 15 & 2.1 & 0.1 & 0.26 & No & Eutrophic & $\mathrm{A}, \mathrm{W}, \mathrm{N}, \mathrm{Z}$ \\
\hline
\end{tabular}

A, air temperature; $\mathrm{W}$, water temperature; $\mathrm{N}$, nutrients (TP, SRP, $\mathrm{NO}_{3}^{-}$and SRSi); $\mathrm{P}$, phytoplankton (diatoms, cyanobacteria and dinoflagellates); Z, zooplankton (daphnids, calanoid copepods and cyclopoid copepods).

$90^{\circ} \mathrm{W}-40^{\circ} \mathrm{E}$ ) from 1980 to 2002 (see also http://www. cgd.ucar.edu/cas/jhurrell/indices.info.html\#naopcdjfm) (Fig. 2). The values of $r$ between the NAO winter index and each of the target variables, computed for each month from January to December, formed the basis for the meta-analysis. In the following, 'NAO' always refers to the winter NAO, a 'positive NAO year' means the year following a winter during which the NAO index was positive, and a 'negative NAO year' means the year following a winter during which the NAO index was negative. 'Significant' means statistically significant at the $P<0.05$ level.

\section{Meta-analysis}

The effects of the winter NAO on monthly values of all target variables at the time of occurrence of specific cardinal events of the plankton succession were tested. We defined five cardinal events (1) winter; (2) the spring phytoplankton bloom; (3) the clear-water phase; (4) the summer phytoplankton bloom; and (5) the summer zooplankton abundance maximum. The respective months of occurrence of these events were defined as: (1) January and February; (2) the lake-specific month in spring with maximum phytoplankton biomass; (3) the lake-specific month in early summer with maximum daphnid abundance (because the clear-water phase is related to maximum daphnid abundance: Straile, 2000); (4) the lake-specific month with the maximum summer phytoplankton biomass and (5) the lake-specific month in summer with maximum zooplankton abundance. Winter, in contrast to the other periods, was defined as 2 months because the extremely low values of the different variables in winter can easily cause spurious 


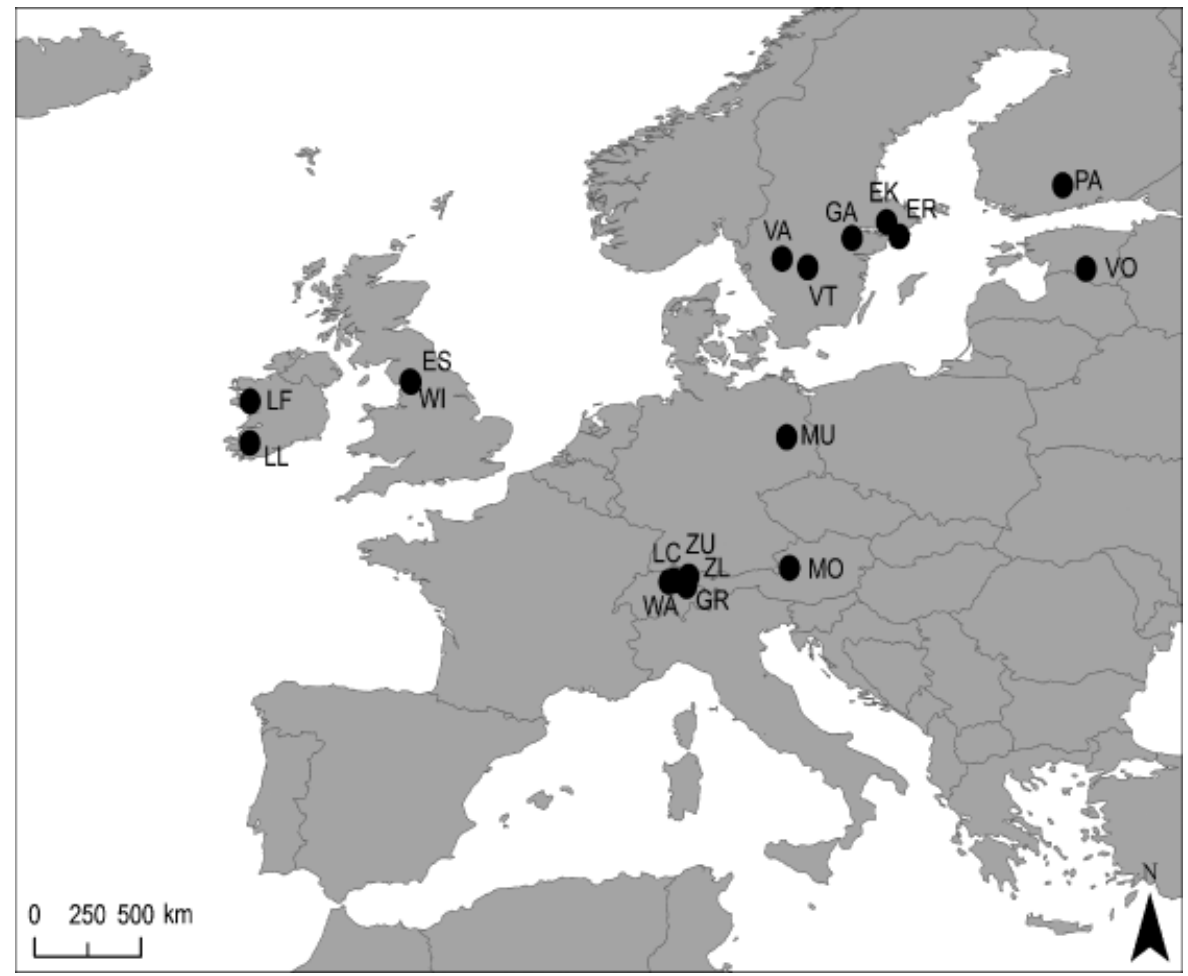

Fig. 1 The geographical locations of the lakes studied. For an explanation of the abbreviations see Table 1.

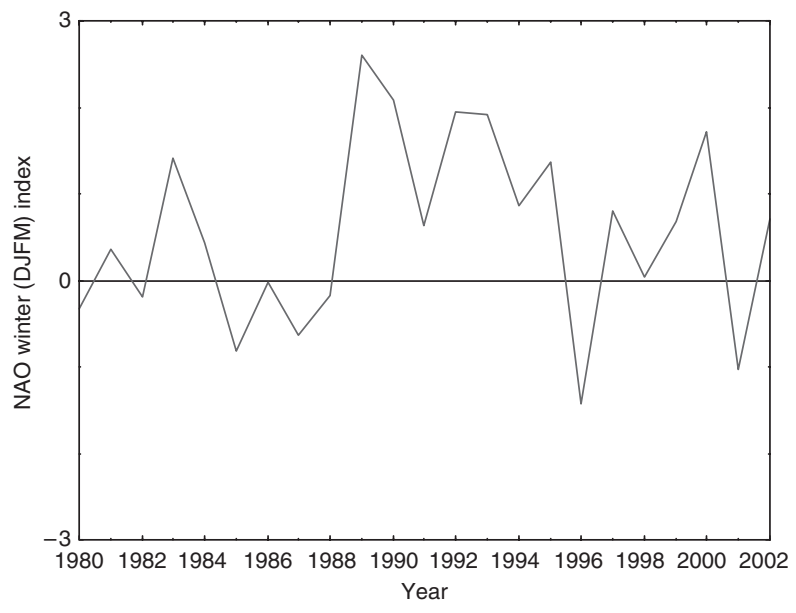

Fig. 2 The time-series of the winter (DJFM) NAO index from 1980 to 2002. Source: http://www.cgd.ucar.edu/cas/jhurrell/ indices.html.

correlations, and because winter sampling in some lakes was very sparse. Henceforth, for simplicity, the above-mentioned periods will be referred to merely as winter, spring, and summer. The times of occurrence of the cardinal events were defined for each lake separately, as a mean over the 23-year period, to account for the average lake-specific seasonal succession pattern of the plankton. The autumn period was excluded from the analysis as the relationship between the winter
$\mathrm{NAO}$ and water temperature overall was not significant after the summer months.

To establish a normalized and variance-stabilized effect size, all correlation coefficients (Pearson's $r$ ) were converted to a normal distribution $\left(r_{z}\right)$ using Fischer's $z$ transform as follows:

$$
r_{z}=\frac{1}{2} \ln \left(\frac{1+r}{1-r}\right)
$$

$r_{z}$ was then used to calculate the effect size. This allows a weighted analysis to be performed, where the effect size is weighted $\left(w_{i}\right)$ for the $i$ th study by the reciprocal of its sampling variance $\left(v_{z}\right)$. The sampling variance of $r_{z}$ was calculated from the number of observations $(n)$ as follows:

$$
v_{z}=\frac{1}{n-3}
$$

We first calculated the overall effect size $\left(E^{++}\right)$of the NAO on air and water temperature and on the lakespecific concentrations of the target chemical and biological lake variables during the five cardinal events mentioned above. We then tested whether the magnitude of the response to the NAO was influenced by eight different characteristics (see also Table 1) that are known to influence the structure and functioning of lake ecosystems. The range of characteristics reflects the type of lakes included in our study. These eight characteristics were: (1) climatic region (Northern, Western, 
and Central Regions); (2) mean lake depth; (3) maximum lake depth; (4) critical depth (the water depth separating bottom areas where mixed deposits and transportation processes dominate from areas of sediment accumulation: see Håkanson et al., 2004); (5) dynamic ratio (ratio of lake surface area to mean lake depth); (6) water residence time; (7) the presence or absence of ice cover; (8) trophic status (oligotrophic, $<10 \mu \mathrm{g} \mathrm{TP} \mathrm{L}^{-1}$; oligo-mesotrophic, ranging from $<10$ to $25 \mu \mathrm{g} \mathrm{TPL}^{-1}$; mesotrophic, ranging from 10 to $25 \mu \mathrm{g} \mathrm{TP} \mathrm{L}^{-1}$; eutrophic, $>25 \mu \mathrm{g} \mathrm{TPL}^{-1}$ ). The meta-analysis was not flawed with respect to outliers, and thus, possible impacts on effect sizes were not due to outliers from one site.

The total overall effect size $\left(E^{++}\right)$and the corresponding 95\% confidence intervals (CI) were calculated for all target variables as outlined by Rosenberg et al. (2000)

$$
E^{++}=\frac{\sum_{i=1}^{n} w_{i} \times E_{i}}{\sum_{i=1}^{n} w_{i}}
$$

where $E_{i}$ is the calculated effect size for the $i$ th study. The variance of $E^{++}$is the reciprocal of the sum of the weights given to each of the $n$ studies:

$$
S_{E^{++}}^{2}=\frac{1}{\sum_{i=1}^{n} w_{i}} .
$$

The confidence interval (CI) of $E^{++}$is then given by

$$
\mathrm{CI}=E^{++} \pm t_{\alpha / 2[n-1]} \times S_{E^{++}},
$$

where $t_{\alpha / 2[n-1]}$ is the two-tailed value of Student's $t$-distribution at the critical level $\alpha$, and $n$ is the number of individual studies.

An overall effect is considered to be significant if the CI does not include zero (Gurevitch et al., 2000). In our study, a positive or negative effect size for a particular variable implies a positive or negative response, respectively, of that variable to the winter NAO. Thus, a significant positive effect size for the water temperature, for example, would imply that overall, a positive winter NAO will result in a significantly higher water temperature and a negative winter NAO in a significantly lower water temperature.

The group effect size $\left(E^{+}\right)$and the CI were calculated for each of the eight above-mentioned characteristics $(j)$ as follows:

$$
E_{j}^{+}=\frac{\sum_{i=1}^{k j} w_{i j} \times r z_{i j}}{\sum_{i=1}^{k j} w_{i j}},
$$

where $k_{j}$ is the number of studies involving characteristic $j$, and $w_{i j}$ and $E_{i j}$ are the weight and effect size for study $i$ and characteristic $j$. For each group effect size, the $95 \%$ CIs were calculated by bootstrapping 999 randomizations. This nonparametric method creates a distribution of effect sizes based on the actual data set without making any assumptions about the form of the underlying distributions. Nonoverlapping CIs indicate significantly different group effect sizes. We tested for differences in effect sizes between characteristics by computing heterogeneity (heterogeneity test, henceforth HT), within groups $\left(Q_{w j}\right)$ and between groups $\left(Q_{M}\right)$, an approach analogous to analysis of variance. The heterogeneity of the $j$ th group is

$$
Q_{w j}=\sum_{i=1}^{k j} w_{i j}\left(E_{i j}-E^{+}\right)^{2} .
$$

The heterogeneity between groups is calculated as

$$
Q_{M}=\sum_{j=1}^{m} \sum_{i=1}^{k j} w_{i j}\left(E^{+}-E^{++}\right)^{2},
$$

where $m=8$ is the number of characteristics. All calculations were performed using MetaWin 2.0 (Rosenberg et al., 2000).

\section{Results}

\section{Temperature}

The effect size for winter air temperature was significant and very large (Fig. 3), showing that this variable is highly correlated with the NAO index and, thus, confirming the suitability of the latter for our purpose. Effect sizes for surface water temperature in winter, spring, and summer were all significant (Fig. 3), implying that high surface temperatures tend to occur in positive NAO years and low surface temperatures in negative NAO years. The strongest signal of the winter NAO in surface temperature was detected in spring. The situation for near-bottom water temperatures was similar (Fig. 3), with correlations being particularly high for lakes with long water residence times (HT, $P<0.001)$ and large critical depths (HT, $P<0.001$; see also Fig. 4).

\section{Nutrients}

SRP and SRSi showed a similar response to the NAO, with effect sizes being of greatest magnitude in spring, when the concentrations of these nutrients tended to be low in positive NAO years and high in negative NAO years (Fig. 3). In winter and summer, variability was much higher than in spring. In positive NAO years, SRSi concentrations in winter were significantly lower in lakes which were not ice-covered than in lakes which were ice-covered $(\mathrm{HT}, P<0.05)$. 


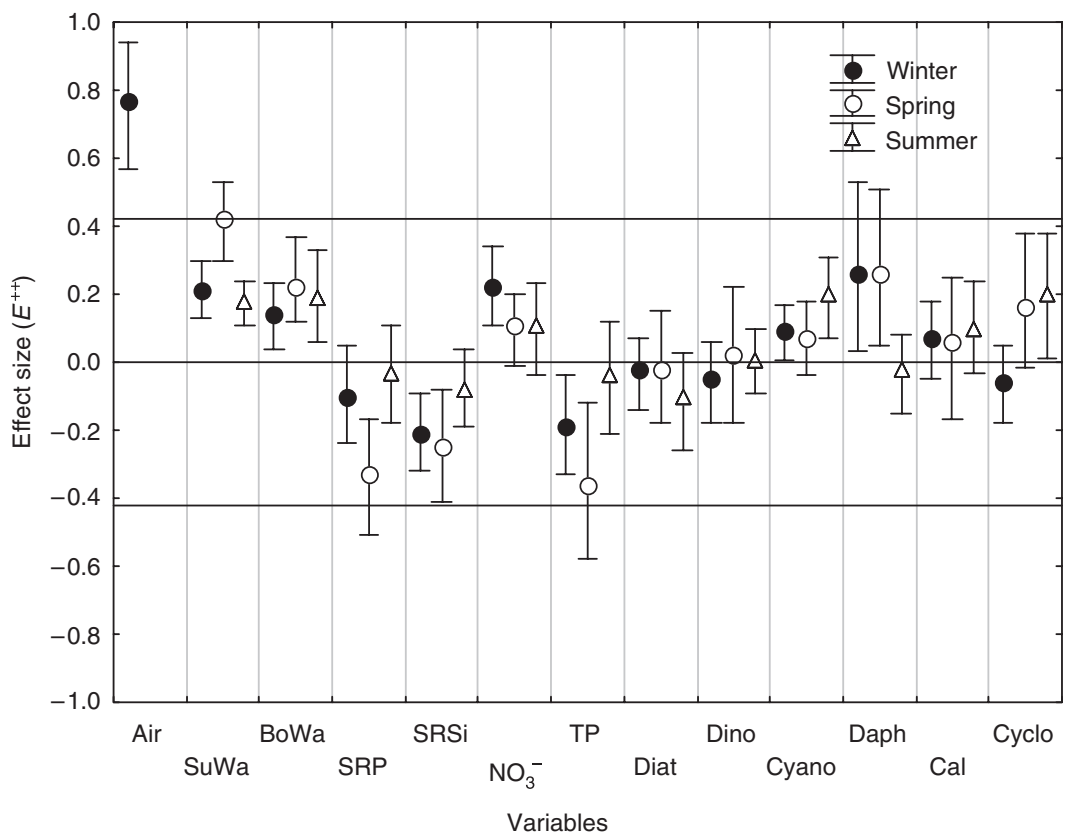

Fig. 3 Overall effect size $\left(E^{++}\right)$and confidence intervals (95\%) for the influence of the winter NAO on the target variables during winter $(\bullet)$ and during the following spring $(\circ)$ and summer $(\triangle)$. Air, air temperature; SuWa, surface water temperature; BoWa, near-bottom water temperature; SRP, soluble reactive phosphorus; SRSi, soluble reactive silicate; $\mathrm{NO}_{3}^{-}$, nitrate; TP, total phosphorus; Diat, diatom biomass; Dino, dinoflagellate biomass; Cyano, cyanobacteria biomass; Daph, Daphnia abundance; Cal, abundance of calanoid copepods; Cyclo, abundance of cyclopoid copepods. The effect size is considered to be significant $(P<0.05)$ if the standard error does not cross the zero line. The horizontal lines above and below the zero line indicate very strong and significant effects $(P<0.01)$.

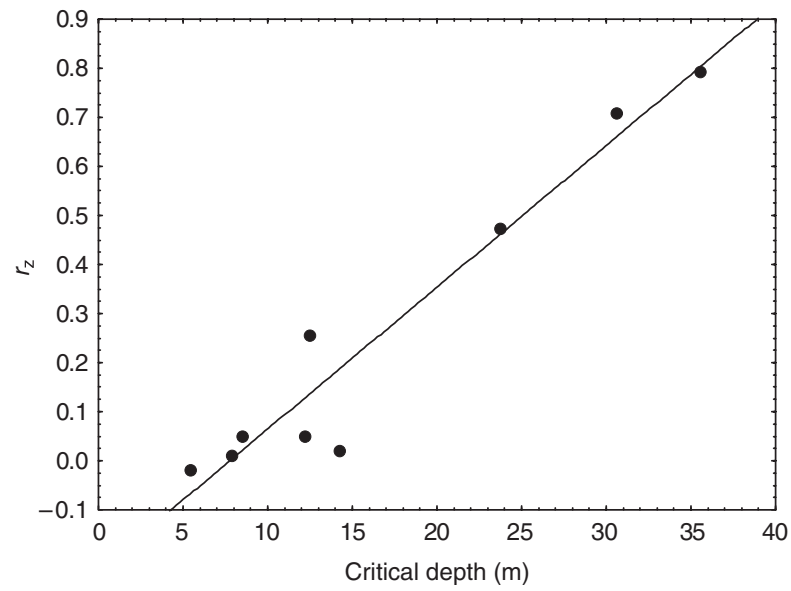

Fig. 4 Relationship between the $z$-transformed correlation coefficient of the winter NAO and the near-bottom water temperature from nine lakes in summer $\left(r_{z}\right)$ and the critical depth as defined by Håkanson et al. (2004).

In contrast to SRP and SRSi, winter $\mathrm{NO}_{3}^{-}$concentrations tended to be high in positive NAO years and low in negative NAO years, especially in lakes with a high dynamic ratio (HT, $P<0.05)$. In spring and summer, variability for $\mathrm{NO}_{3}^{-}$was high and the effect size was not significant.
Winter and spring TP concentrations tended to be low in positive NAO years and high in negative NAO years (Fig. 3). In general, spring TP concentrations tended to be higher in lakes with a high dynamic ratio than in lakes with a low dynamic ratio (HT, $P<0.05)$. However, variability was high, presumably because of lakespecific differences. For example, the correlation coefficients were significantly negative in only five lakes, (i.e. in oligotrophic Walensee, in mesotrophic Lake Erken, and in the eutrophic lakes Greifensee, Upper Lake Zurich and Lower Lake Zurich). No other lakes showed a significant response. The response of TP to the NAO was not significantly related to the trophic status of the lake $(\mathrm{HT}, P=0.65)$

\section{Plankton}

In none of the seasons studied did the diatom biomass show any relationship to the winter NAO (Fig. 3). This also holds for the dinoflagellate and cyanobacterial biomass in winter and spring. Interestingly, we found a significant positive relationship between the summer cyanobacterial biomass and the NAO [i.e. the cyanobacterial biomass was higher in positive than in negative NAO years (Fig. 3)], with no significant differences in the effect based on the categories chosen in the HT. 
The maximum abundance of daphnids in winter and spring showed a significant positive relationship with the NAO, although lake-to-lake variability was high, especially during winter. Calanoid copepods, which are usually present throughout the year, showed no overall relationship to the NAO in any season. The abundance of cyclopoid copepods in summer was significantly higher in positive NAO years than in negative NAO years. During spring the same tendency was observed, but this tendency was not strong enough to be statistically significant (Fig. 3).

\section{Discussion}

\section{Climate-induced variability in air and water temperatures}

Overall, we found the strongest coherent response to the winter NAO in the temperature variables (air temperature, surface temperature, and near-bottom temperature). The effect of the winter NAO on near-bottom temperatures was strongest in the case of lakes with long water residence times and large critical depths (Fig. 4). This is to be expected, as deep-water temperatures during summer stratification, especially in deep lakes, are generally determined by the mean lake temperature attained during spring turnover (Livingstone, 1993; Gerten \& Adrian, 2001; Straile et al., 2003a). Overall, the strength of the relationship between water temperature and NAO found in all lakes included in the study confirms the importance of the NAO as a climatic driver across all three climate regions.

\section{Climate-induced variability in nutrient concentrations}

The underlying mechanisms driving nutrient concentrations are complex, as they are influenced by catchment-related processes, nutrient uptake by the phytoplankton, shifts in phytoplankton phenology, water level, and interactions with the lake sediment. Thus, nutrient responses might be expected to be strongly site-specific. However, both SRP and SRSi concentrations in spring were found to exhibit a strongly coherent response to the previous winter's $\mathrm{NAO}$, with both being negatively correlated with the winter NAO index. This was probably because an advance in spring phytoplankton phenology in positive NAO years, which has been observed in several lakes (Weyhenmeyer et al., 1999; Gerten \& Adrian, 2000; Winder \& Schindler, 2004), would result in earlier nutrient uptake (Sommer et al., 1986), while a retardation of spring phytoplankton phenology in negative NAO years would result in later nutrient uptake (Pettersson et al., 2003). The finding that the overall response to the NAO was independent of the trophic

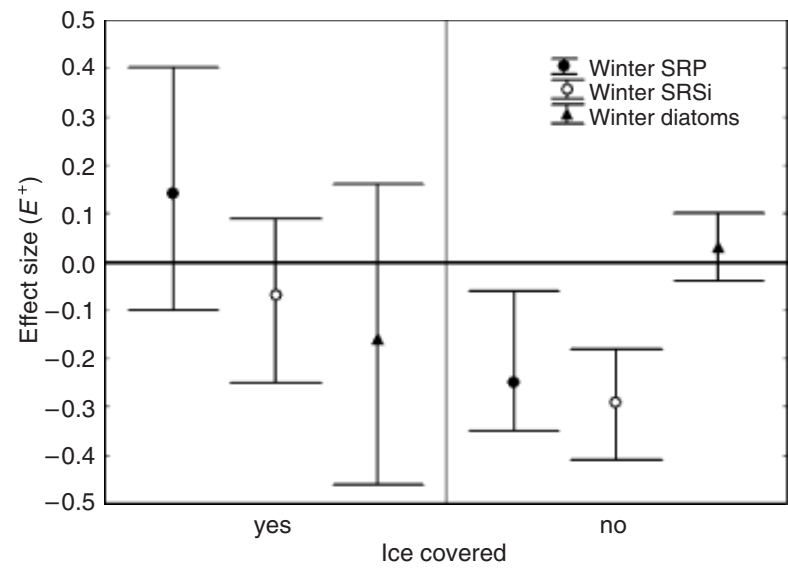

Fig. 5 Group effect size $\left(E^{+}\right)$and confidence intervals (95\%) for winter SRP and SRSi concentrations and winter diatom biomass in lakes with and without ice cover.

status of the lake is consistent with the fact that most lakes are nutrient limited by the time algal biomass peaks in spring. The low SRP and SRSi concentrations in positive NAO years were not reflected in an overall early increase in winter diatom biomass. However, the occurrence of higher biomass could have been missed because of the overrepresentation of lakes with a relatively low (monthly) sampling frequency. Phytoplankton spring blooms are naturally short lived because nutrient depletion and losses through grazing and sedimentation occur rapidly and act on short temporal scales (Sommer et al., 1986).

Moreover, the overall significance of the SRP and SRSi signals during winter might have been negatively affected by the presence of signals of opposite sign in lakes with and without ice cover (Fig. 5). The heterogeneity test, however, yielded a significant result only for SRSi. In lakes with no ice cover and a high degree of turbulence in the water column, diatoms may grow all winter, especially in positive NAO years, and could, therefore, cause a decrease in SRSi and SRP concentrations. The development of an especially high winter diatom biomass in ice-free winters in Müggelsee supports such a hypothesis (Adrian et al., 1999). In ice-covered lakes, inverse thermal stratification and low light intensities, partly due to snow cover on the ice, are likely to reduce diatom growth under the ice (Weyhenmeyer et al., 1999), resulting in a winter diatom biomass that is lower than that found in lakes with no ice cover. We see a tendency for this effect to occur (Fig. 5) but the effect remains statistically insignificant. In the meta-analysis, the two opposing mechanisms in ice-covered and ice-free lakes will, to a large extent, cancel each other out, resulting in the winter diatom biomass exhibiting no overall change. Furthermore, in 
deep lakes in which the NAO affects deep-water mixing, warm winters (positive NAO years) may prevent the complete upward mixing of nutrients (Verburg et al., 2003), resulting in a negative correlation between nutrient concentrations and the NAO index (Straile et al., 2003a).

In contrast to SRP and SRSi, winter $\mathrm{NO}_{3}^{-}$concentrations were generally positively correlated with the NAO (Fig. 3). The underlying processes are rather unclear, as all lake characteristics used in the heterogeneity tests were found to be insignificant. George et al. (2004a) explained the positive relationship between $\mathrm{NO}_{3}^{-}$concentrations in late winter and the NAO in terms of the flushing of $\mathrm{NO}_{3}^{-}$from the catchment into the lakes by melt water, which occurred earlier in positive NAO years than in negative NAO years. Moreover, mild winters may lead to increased nutrient leaching from catchment soils that have not yet frozen. While we found a positive relationship between $\mathrm{NO}_{3}^{-}$concentrations and the NAO overall, in the United Kingdom the relationship was negative, probably because of the enhanced terrestrial uptake of $\mathrm{NO}_{3}^{-}$during very mild winters (Straile et al., 2003b; George et al., 2004b; Blenckner, 2005). It is possible that the positive correlation between the $\mathrm{NAO}$ and $\mathrm{NO}_{3}^{-}$in the Northern and Central Regions, and the negative correlation in the Western Region, reflect the temperature gradient that exists in Europe between the continental and maritime climate regions. During winters in which the NAO index is low, air temperatures in the Western Region are still generally much higher (mostly above freezing) than in the Northern and Central Regions. In addition, during winters in which the NAO index is high, the Northern and Central Regions will normally have above-average amounts of snow, which in the Western Region is generally not the case. Earlier and deeper snow cover in negative NAO years insulates the soil from the low air temperatures and reduces the effects of freezing on soil processes (Brooks et al., 1999; Schimel et al., 2004). In contrast, more frost days would be expected in negative NAO years in the Western Region. A three-way relationship between the number of days with soil temperatures below $-4{ }^{\circ} \mathrm{C}$, peak winter $\mathrm{NO}_{3}^{-}$ concentrations in a stream, and the NAO has been reported for an upland catchment in the United Kingdom, with both the number of frost days and nitrate concentrations being higher than average in negative NAO years (Monteith et al., 2000). We hypothesize that the effect of the number of frost days, together with earlier flushing by melt water (George et al., 2004a) and a higher total nitrogen deposition (due to more precipitation in positive NAO years), may result in a higher $\mathrm{NO}_{3}^{-}$transport from the catchments into the lakes. That would mean that the direction of the $\mathrm{NO}_{3}^{-}-\mathrm{NAO}$ relationship is opposite to that of the soil temperatureNAO relationship in both cases.

\section{Climate-induced variability in plankton}

The higher abundances of daphnids during spring in positive NAO years can be attributed to the observed advance in the timing of the daphnid abundance maximum in many European lakes rather than to an overall increase in abundance (Straile \& Adrian, 2000; Straile, 2002). This emphasizes the need to correct for known phenological shifts when defining the seasons (which was done in this study). The positive signal for daphnids in winter has to be regarded with caution. There may be an increasing tendency towards over-wintering for individuals in the pelagic zone related to an increase in water temperature in winter (George \& Hewitt, 1999), but this is very difficult to detect, as winter abundances in almost all years were at the limit of detection.

During summer, however, we found a strong NAO signal, implying enhanced biomass for cyanobacteria and cyclopoid copepods in positive NAO years (Fig. 3). Cyanobacteria may have profited from direct temperature effects (Robarts \& Zohary, 1987) and the extension of the period of stratification. Early summer stratification may enable earlier cyanobacterial growth (Weyhenmeyer, 2001; Järvinen et al., 2006). Enhanced predation pressure on edible algal prey by omnivorous summer cyclopoid copepods could have additionally favoured the development of cyanobacteria (Gerten \& Adrian, 2002b; Blenckner, 2005).

Although previous studies have found the abundance of calanoid copepods to be related to the NAO in both freshwater habitats (George, 2000) and marine habitats (Fromentin \& Planque, 1996), we were not able to confirm this in the present study (Fig. 3). The abundance of cyclopoid copepods, however, did respond to NAO variability. In a study on Müggelsee, Gerten \& Adrian (2002b) assumed that high spring water temperatures led to the early emergence of copepodid resting stages, and subsequently to early maturity, as the magnitude of the summer abundance maximum was correlated with water temperature in spring. This suggests that the appearance of copepodid resting stages in the pelagic zone more than 1 month earlier than usual allows the development of an extra generation (three instead of two), which may have contributed to the enhanced peak abundances during summer (Gerten \& Adrian, 2002b). For Thermocyclops oithonoides it has been shown that higher water temperatures do indeed allow the completion of a further generation (Naess et al., 1993). As the other lakes included in this study experienced similar warming trends to those observed in Müggelsee, a similar mechanism may hold 
for the general increase in summer cyclopoid copepods in European lakes. We do, however, also know that the type of response of summer cyclopoid species to warming is very much species-specific (Gerten \& Adrian, 2002b; Adrian et al., 2006).

\section{Synthesis}

Within the past decade, substantial progress has been made in identifying the direct and indirect effects of climatic forcing on lake ecosystems (Schindler, 2001; Gerten \& Adrian, 2002a; Straile et al., 2003b; Blenckner, 2005) and in confirming the existence of a large-scale coherent response (Kratz et al., 1997; George et al., 2000; Livingstone \& Dokulil, 2001; Straile, 2002). Integrated responses, in the sense of several overlapping driving mechanisms, are probably the most common responses of all, and, given their complex nature, the most difficult to detect (Blenckner, 2005). For example, the effects of the interaction between a warming trend and a reduction in nutrient loading resulting from anthropogenic and/or climate-induced changes in lake catchments are as yet poorly understood, and thus difficult to predict within the context of future climate change scenarios. The emphasis in this study is on climatic effects. We would, however, like to point out that co-variation with other ecosystem drivers - such as reductions in nutrient loading, recovery from acidification, changes in the stratification pattern and other, still unknown, processes - cannot be excluded. We suggest that climatic factors modify the responses of ecosystems to anthropogenically induced changes, such as nutrient reduction (Schindler et al., 1996). We also need to keep in mind the fact that our study focuses mainly on linear relationships between the target variables and the winter NAO, even though some of the interactions involved - in particular the indirect and integrated responses - may in fact be nonlinear (May, 1986). Moreover, the response lag looked at in this study extended up to a maximum of five months (from the winter NAO to the summer maximum zooplankton biomass). In some cases, however, the response can lag the forcing by over a year (Ottersen et al., 2001; Straile et al., 2003b, 2007), depending on the water residence time of the lake and the life-cycles of the organisms concerned.

In conclusion, this quantitative synthesis, based on 23 years of physical, chemical, and biological data from 18 lakes located in three disparate geographical regions in Europe, shows the existence of a high degree of coherence in the behaviour of water temperature from winter to summer, nutrient concentrations in spring, and the biomass of cyanobacteria and cyclopoid copepods in summer. This coherent behaviour is related to the interannual variability of the winter NAO, which

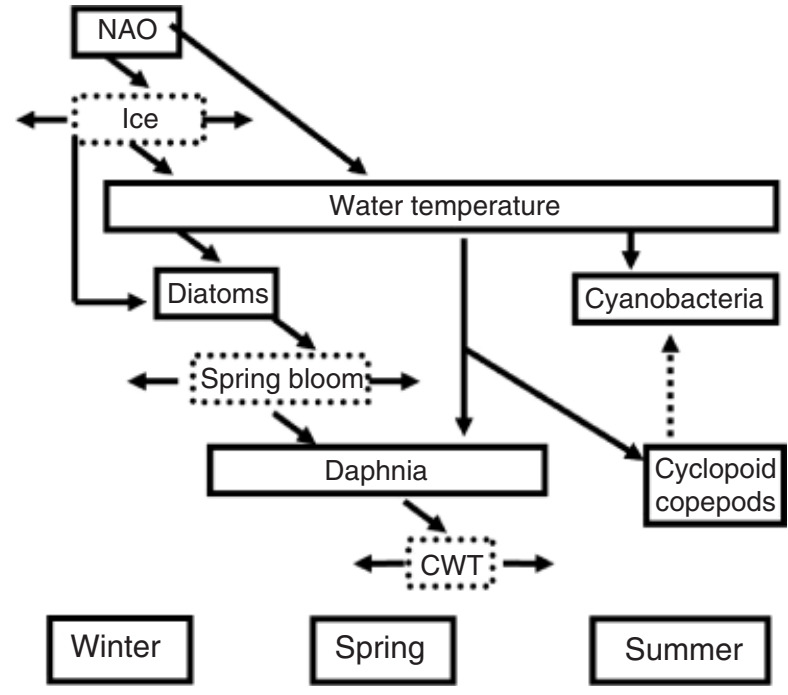

Fig. 6 Schematic overview of the effects of the winter NAO on lake ecosystems. The overview is an extension of the concept developed by Straile (2002). The time periods covered by the boxes indicate the periods of the year during which causal links exist between the winter NAO and lake water temperatures, and during which subsequent cascading effects can be detected along different trophic levels. Boxes bordered by dotted lines indicate phenological events. Horizontal arrows denote the advance or retardation of phenological events in time. The winter NAO has a strong effect on the timing of ice break-up and on water temperature in winter, spring and summer. The timing of ice break-up influences the initial growth conditions for diatoms, and thereby the timing of the spring phytoplankton bloom. The water temperature in spring directly influences the growth of Daphnia, and thereby the timing of the clear-water phase. Water temperatures in spring and summer influence the biomass of cyanobacteria and cyclopoid copepods in summer both directly and indirectly (e.g. via the duration of the summer stratification period). A high abundance of cyclopoid copepods during years with high spring water temperatures may enhance the predation pressure on edible algal prey, which could additionally favour cyanobacteria biomass in summer (indicated by a dashed line).

appears to induce a strong climatic signal across all three climatic regions included in this study. Given the strong response to the winter NAO exhibited by spring plankton phenology (not shown here), the coherent nutrient depletion in spring in positive NAO years was partly driven by the advance in spring phytoplankton phenology in those years (see Fig. 6). However, the high variability reflects the complex, system-specific conditions existing in the catchments of the lakes. Cyanobacteria obviously profit both from direct temperature effects and from indirect temperature effects acting through the extension of the period of thermal stratification in positive NAO years, while copepods are likely to profit from enhanced temperatures. Overall, 
our meta-analysis confirms the existence of climatic signatures detected in individual lake studies that result from processes driven both directly by temperature and indirectly by biotic interactions. Straile (2002) summarized climate-induced changes along pelagic food webs for the winter/spring situation in a schematic figure. Figure 6 represents an extension of this schematic figure to include the summer situation. The interplay between responses driven directly and indirectly by temperature may turn out to be more complex during summer, given the higher proportion of inedible algal prey such as cyanobacteria and slowly growing zooplankton species which exhibit complex life cycles. Moreover, changes in summer cyanobacteria biomass and cyclopoid copepod abundances are likely to be related to changes in spring water temperature (Fig. 6).

\section{Outlook}

A challenge for future climate impact studies is to estimate how lake ecosystems will respond to further climate warming, as projected for instance by Räisänen et al. (2004). Based on such climate scenarios, which predict further winter and spring warming, the period of ice cover for lakes in southern Sweden and Finland is likely to be interrupted by periods of open water (Elo et al., 1998), or the lakes may experience years with no ice cover at all (the current situation in many lakes in the Western and Central Regions; e.g. Adrian \& Hintze, 2000). Day-length-specific water temperatures appear to be crucial for setting thresholds in spring, as they are important drivers of phytoplankton development (Reynolds, 1984), but are also important cues for emerging zooplankton resting stages (Cáceres, 1998; Vandekerkhove et al., 2005). Enhanced remineralization of nutrients and higher diffusion rates at higher temperatures, combined with a longer ice-free period, will enhance the availability of nutrients to algae, especially in lakes with a long water residence time (Blenckner et al., 2002). During summer, the extension of the stratified period, or more stable stratification and higher water temperatures, may set the boundaries for the structure of future summer plankton communities and the likelihood of species invasion. The bloom-forming cyanobacterium Cylindrospermopsis raciborskii, a primarily tropical and sub-tropical species, is, for example, currently invading Europe and North America (Briand et al., 2004). Although our study provides little evidence for a decoupling of currently established food web interactions from one another, further changes in phenology, or the invasion or loss of species under future climate scenarios, may indeed increase the likelihood of a mismatch of interactions within plankton communities.

\section{Acknowledgements}

This study was funded by the European Commission project CLIME ('Climate and Lake Impacts in Europe', EVK1-CT-200200121). We are grateful to Helmut Hillebrand and two anonymous reviewers for their comments on the manuscript.

\section{References}

Adrian R, Hintze T (2000) Effects of winter air temperature on the ice phenology of the Müggelsee (Berlin, Germany). Verhandlungen der Internationalen Vereinigung der Limnologie, 27, 2808-2811.

Adrian R, Walz N, Hintze Tet al. (1999) Effects of ice duration on plankton succession during spring in a shallow polymictic lake. Freshwater Biology, 41, 621-632.

Adrian R, Wilhelm S, Gerten D (2006) Life history traits of lake plankton species may govern their phenology response to climate warming. Global Change Biology, 12, 652-661.

Anneville O, Souissi S, Gammeter S et al. (2004) Seasonal and inter-annual scales of variability in phytoplankton assemblages: comparison of phytoplankton dynamics in three peri-alpine lakes over a period of 28 years. Freshwater Biology, 49, 98-115.

Blenckner T (2005) A conceptual model of climate related effects on lake ecosystems. Hydrobiologia, 533, 1-14.

Blenckner T, Hillebrand H (2002) North Atlantic Oscillation signatures in aquatic and terrestrial ecosystems - a metaanalysis. Global Change Biology, 8, 203-212.

Blenckner T, Omstedt A, Rummukainen M (2002) A Swedish case study of contemporary and possible future consequences of climate change on lake function. Aquatic Science, 64, 171-184.

Briand J, Leboulanger C, Humbert J et al. (2004) Cylindrospermopsis raciborskii (Cyanobacteria) invasion at mid-latitudes: selection, wide physiological tolerance, or global warming? Journal of Phycology, 40, 231-238.

Brooks PD, Campbell DH, Tonnessen KA et al. (1999) Natural variability in $\mathrm{N}$ export from headwater catchments: snow cover controls on ecosystem $\mathrm{N}$ retention. Hydrological Processes, 13, 2192-2201.

Cáceres CE (1998) Interspecific variation in the abundance, production, and emergence of Daphnia diapausing eggs. Ecology, 79, 1699-1710.

Edinger JE, Duttweiler DW, Geyer JC (1968) The response of water temperature to meteorological conditions. Water Resources Research, 8, 1137-1143.

Edwards M, Richardson AJ (2004) Impact of climate change on marine pelagic phenology and trophic mismatch. Nature, 430, 881-884.

Elo A-R, Huttula T, Peltonen A et al. (1998) The effects of climate change on the temperature conditions of lakes. Boreal Environment Research, 3, 137-150.

Fromentin JM, Planque B (1996) Calanus and environment in the eastern North Atlantic. II. Influence of the North Atlantic Oscillation on C. finmarchicus and C. helgolandicus. Marine Ecology Progress Series, 134, 111-118.

George DG (2000) The impact of regional-scale changes in the weather on the long-term dynamics of Eudiaptomus and 
Daphnia in Esthwaite Water, Cumbria. Freshwater Biology, $\mathbf{4 5}$ 111-121.

George DG, Hewitt DP (1999) The influence of year-to-year variations in the winter weather on the dynamics of Daphnia and Eudiaptomus in Esthwaite Water, Cumbria. Functional Ecology, 13, 45-54.

George DG, Järvinen M, Arvola L (2004a) The influence of the North Atlantic Oscillation on the winter characteristics of Windermere (UK) and Pääärvi (Finland). Boreal Environment Research, 9, 389-399.

George DG, Maberly SC, Hewitt DP (2004b) The influence of the North Atlantic Oscillation on the physical, chemical and biological characteristics of four lakes in the English Lake District. Freshwater Biology, 49, 760-774.

George DG, Talling JF, Rigg E (2000) Factors influencing the temporal coherence of five lakes in the English Lake District. Freshwater Biology, 43, 449-461.

Gerten D, Adrian R (2000) Climate-driven changes in spring plankton dynamics and the sensitivity of shallow polymictic lakes to the North Atlantic Oscillation. Limnology and Oceanography, 45, 1058-1066.

Gerten D, Adrian R (2001) Differences in the persistency of the North Atlantic Oscillation signal among lakes. Limnology and Oceanography, 46, 448-455.

Gerten D, Adrian R (2002a) Effects of climate warming, North Atlantic Oscillation, and El Niño-Southern Oscillation on thermal conditions and plankton dynamics in Northern Hemispheric Lakes. The Scientific World Journal, 2, 586-606.

Gerten D, Adrian R (2002b) Species-specific changes in the phenology and peak abundance of freshwater copepods in response to warm summers. Freshwater Biology, 47, 2163-2173.

Gurevitch J, Morrison JA, Hedges LV (2000) The interaction between competition and predation: a meta-analysis of field experiments. American Naturalist, 155, 435-453.

Gurevitch J, Morrow LL, Wallace A et al. (1992) A meta-analysis of competition in field experiments. American Naturalist, 140, 539-572.

Hagberg J, Tunberg BG (2000) Studies on the covariation between physical factors and the long-term variation of the marine soft bottom macrofauna in Western Sweden. Estuarine, Coastal and Shelf Science, 50, 373-385.

Håkanson L, Blenckner T, Malmaeus JM (2004) New, general methods to define the depth separating surface water from deep water, outflow and internal loading for mass-balance models for lakes. Ecological Modelling, 175, 339-352.

Hurrell JW (1995) Decadal trends in the North Atlantic Oscillation: regional temperatures and precipitation. Science, 269, 676-679.

Järvinen M, Lehtinen S, Arvola L (2006) Variations in phytoplankton assemblage in relation to environmental and climatic variation in a boreal lake. Verhandlungen der Internationalen Vereinigung der Limnologie, 29, 1841-1844.

Köhler J, Hilt S, Adrian R et al. (2005) Long-term response of a shallow, moderately flushed lake to reduced external phosphorus and nitrogen loading. Freshwater Biology, 50, 1639-1650.

Kratz TK, Webster KE, Bowser CJ et al. (1997) The influence of landscape position on lakes in northern Wisconsin. Freshwater Biology, 37, 209-217.
Livingstone DM (1993) Temporal structure in the deep-water temperature of four Swiss lakes: a short-term climatic change indicator? Verhandlungen der Internationalen Vereinigung der Limnologie, 25, 75-81.

Livingstone DM (2000) Large-scale climatic forcing detected in historical observations of lake ice break-up. Verhandlungen der Internationalen Vereinigung der Limnologie, 27, 2775-2783.

Livingstone DM, Dokulil MT (2001) Eighty years of spatially coherent Austrian lake surface temperatures and their relationship to regional air temperature and the North Atlantic Oscillation. Limnology and Oceanography, 46, 1220-1227.

Livingstone DM, Lotter AF, Kettle H (2005) Altitude-dependent differences in the primary physical response of mountain lakes to climatic forcing. Limnology and Oceanography, 50, 1313-1325.

Magnuson JJ, Benson BJ, Kratz TK (1990) Temporal coherence in the limnology of a suite of lakes in Wisconsin, USA. Freshwater Biology, 23, 145-159.

May RM (1986) When two and two do not make four: nonlinear phenomena in ecology. Proceedings of the Royal Society of London Series B: Biological Sciences, 228, 241-266.

Monteith DT, Evans CD, Reynolds B (2000) Are temporal variations in the nitrate content of UK upland freshwaters linked to the North Atlantic Oscillation? Hydrological Processes, 14, 1745-1749.

Naess T, Nilssen JP, Demmo R (1993) Individual lake characteristics modify life cycle and diapause habitat of two neighboring populations of the cyclopoid copepod Thermocyclops oithonoides. Canadian Journal of Zoology, 71, 1663-1672.

Nõges T, Laugaste R, Loigu E et al. (2005) Is the destabilisation of lake Peipsi ecosystem caused by increased phosphorus loading or decreased nitrogen loading? Water Science and Technology, 57, 267-274.

Oschlies A (2001) NAO-induced long-term changes in nutrient supply to the surface waters of the North Atlantic. Geophysical Research Letters, 28, 1751-1754.

Osenberg CW, Sarnell O, Cooper SD et al. (1999) Resolving ecological questions though meta-analysis: goals, metrics and models. Ecology, 80, 1105-1117.

Ottersen G, Planque B, Belgrano A et al. (2001) Ecological effects of the North Atlantic Oscillation. Oecologia, 128, 1-14.

Pettersson K, Grust K, Weyhenmeyer GA et al. (2003) Seasonality of chlorophyll and nutrients in Lake Erken - effects of weather conditions. Hydrobiologia, 506-509, 75-81.

Räisänen J, Hansson U, Ullerstig A et al. (2004) European climate in the late twenty-first century: regional simulations with two driving global models and two forcing scenarios. Climate Dynamics, 22, 13-31.

Reynolds C (1984) The Ecology of Freshwater Phytoplankton. Cambridge University Press, Cambridge.

Robarts RD, Zohary T (1987) Temperature effects on photosynthetic capacity, respiration, and growth rates of bloom-forming cyanobacteria. New Zealand Journal of Marine and Freshwater Research, 21, 391-399.

Rosenberg MS, Adams DC, Gurevitch J (2000) MetaWin Version 2.0 Statistical Software for Meta-Analysis. Sinauer, Sunderland.

Schimel JP, Bilbrough C, Welker JM (2004) Increased snow depth affects microbial activity and nitrogen mineralization in two Arctic tundra communities. Soil Biology and Biochemistry, 36, 217-227. 
Schindler DW (2001) The cumulative effects of climate warming and other human stresses on Canadian freshwaters in the new millennium. Canadian Journal of Fisheries and Aquatic Sciences, $58,18-29$.

Schindler DW, Bayley SE, Parker BR et al. (1996) The effects of climate warming on the properties of boreal lakes and streams at the Experimental Lakes Area, northwestern Ontario. Limnology and Oceanography, 41, 1004-1017.

Sommer U, Gliwicz ZM, Lampert W et al. (1986) The Plankton Ecology Group model of seasonal succession of planktonic events in fresh waters. Archiv für Hydrobiologie, 106, 433-472.

Stenseth NC, Mysterud A, Ottersen G et al. (2002) Ecological effects of climate fluctuations. Science, 297, 1292-1296.

Straile D (2000) Meteorological forcing of plankton dynamics in a large and deep continental European lake. Oecologia, 122, $44-50$.

Straile D (2002) North Atlantic Oscillation synchronizes food-web interactions in central European lakes. Proceedings of the Royal Society of London, Series B: Biological Sciences, 269, 391-395.

Straile D, Adrian R (2000) The North Atlantic Oscillation and plankton dynamics in two European lakes - two variations on a general theme. Global Change Biology, 6, 663-670.

Straile D, Eckmann R, Jüngling Tet al. (2007) Influence of climate varibility on whitefish (Coregonus lavaretus) year-class strength in a deep, warm monomictic lake. Oecologia, 151, 521-529.

Straile D, Joehnk K, Rossknecht H (2003a) Complex effects of winter warming on the physicochemical characteristics of a deep lake. Limnology and Oceanography, 48, 1432-1438.

Straile D, Livingstone DM, Weyhenmeyer GA et al. (2003b) The response of freshwater ecosystems to climate variability associated with the North Atlantic Oscillation. In: The North Atlantic Oscillation, Climatic Significance and Environmental Im- pact. Geophysical Monograph 134 (eds Hurrell JW, Kushnir Y, Ottersen G, Visbeck M), pp. 263-279. American Geophysical Union, Washington, DC.

Thomas CD, Cameron A, Green RE et al. (2004) Extinction risk from climate change. Nature, 427, 145-148.

Vandekerkhove J, Declerck S, Brendonck L et al. (2005) Hatching of cladoceran resting eggs: temperature and photoperiod. Freshwater Biology, 50, 96-104.

Verburg P, Hecky RE, Kling H (2003) Ecological consequences of a century of warming in Lake Tanganyika. Science, 301, 505-507.

Walker GT, Bliss EW (1932) World weather V. Memoirs of the Royal Meteorological Society, 4, 53-84.

Walther GR, Post E, Convey P et al. (2002) Ecological responses to recent climate change. Nature, 416, 389-395.

Wang C, Fiedler PC (2006) ENSO variability and the eastern tropical Pacific: a review. Progress in Oceanography, 69, 239-266.

Weyhenmeyer GA (2001) Warmer winters: are planktonic algal populations in Sweden's largest lakes affected? Ambio, 30, 565-571.

Weyhenmeyer GA (2004) Synchrony in relationships between the North Atlantic Oscillation and water chemistry among Sweden's largest lakes. Limnology and Oceanography, 49, 1191-1201.

Weyhenmeyer GA, Blenckner T, Pettersson K (1999) Changes of the plankton spring outburst related to the North Atlantic Oscillation. Limnology and Oceanography, 44, 1788-1792.

Weyhenmeyer GA, Meili M, Livingstone DM (2004) Nonlinear temperature response of lake ice breakup. Geophysical Research Letters, 31, L07203, doi: 10.1029/2004GL019530.

Winder M, Schindler DE (2004) Climate change uncouples trophic interactions in an aquatic ecosystem. Ecology, 85, 2100-2106. 